\title{
Influence of high velocity oxy-fuel parameters on properties of nanostructured $\mathrm{TiO}_{2}$ coatings
}

\author{
MARYAMOSSADAT BOZORGTABAR*, MEHDI SALEHI ${ }^{\dagger \dagger}$, \\ MOHAMMADREZA RAHIMIPOUR ${ }^{\dagger}$ and MOHAMMADREZA JAFARPOUR ${ }^{\dagger \dagger \dagger}$ \\ Islamic Azad University-Majlesi Branch, Majlesi New Town, Isfahan, Iran \\ ${ }^{\dagger}$ Materials and Energy Research Centre, P. O. Box 14155-4777, Tehran, Iran \\ ${ }^{\dagger}$ Department of Materials Engineering, Isfahan University of Technology, Isfahan 84154, Iran \\ ${ }^{\dagger \dagger}$ Mobarakeh Steel Company, P. O. Box 84815-161, Isfahan, Iran
}

MS received 28 May 2009; revised 5 July 2009

\begin{abstract}
A liquid fuel high velocity oxy-fuel (HVOF) thermal spray process has been used to deposit $\mathrm{TiO}_{2}$ nanostructured coatings utilizing a commercially available nanopowder as the feedstock. The coatings were characterized by means of X-ray diffraction analysis (XRD), scanning electron microscopy (SEM) and transmission electron microscope (TEM), respectively. Photocatalytic activity was evaluated as a rate constant of decomposition reaction of methylene blue (MB) determined from the changes of relative concentration of MB with $\mathrm{UV}$ irradiation time. The results indicate that the sprayed $\mathrm{TiO}_{2}$ coatings were composed of both $\mathrm{TiO}_{2}$ phases viz. anatase and rutile, with different phase contents and crystallite sizes. A high anatase content of $80 \%$ by volume was achieved at 0.00015, fuel-to-oxygen ratio with nanostructure coating by grain size smaller than feedstock powder. Photocatalytic activity evaluation results indicated that all the $\mathrm{TiO}_{2}$ coatings are effective to degradation $\mathrm{MB}$ under $\mathrm{UV}$ radiation and their activities differ in different spray conditions. It is found that fuel flow rate strongly influenced on phase transformation of anatase to rutile and by optimizing the rate which can promote structural transformation and grain coarsening in coating and improving photocatalytic activity.
\end{abstract}

Keywords. HVOF; $\mathrm{TiO}_{2}$; phase transformation; nanostructure coating.

\section{Introduction}

In high velocity oxy-fuel (HVOF) thermal spraying, a gaseous or liquid fuel is pre-mixed with oxygen at high pressure and flow rates, before entering an internal combustion chamber. The oxy-fuel mixture is continuously ignited and the combustion products accelerated along the gun barrel nozzle to produce a supersonic flame $(\sim 2000 \mathrm{~m} / \mathrm{s})$. In liquid-fuelled HVOF, guns are normally designed with a convergent-divergent nozzle, which gives superior acceleration to the gas flow and high momentum output to powder particles (Kamnis and Gu 2006). Powder is normally fed into the hot gas stream at downstream of the nozzle instead of being directly fed into combustion chambers, which effectively reduces overheating to powder particles and contributes to the unique feature of high powder impact velocity without overheating. The combustion of liquid fuel, such as kerosene is very complicated, due to the large variation of composition and fuel quality. Altering the gas flows and mixing ratios, the ratio of fuel

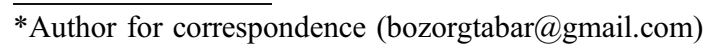

to oxygen, will influence both the flame's temperature and velocity (Hearley and Little 2000).

HVOF thermal spray can provide an efficient way for depositing coatings of nanostructured materials because: (i) the powder particles hit the substrate with relatively high speed, which produces coatings with high density and (ii) relatively low gas temperature prevents particles from being superheated during flight and helps to preserve the nanocrystalline structure of powders deposited on the substrate (Kim 2007).

The studies performed in recent years showed that the thermal spray technique could be employed to obtain $\mathrm{TiO}_{2}$ coatings with an effective photocatalytic performance for the decomposition of organic compounds (Kanazawa and Ohmori 2005). $\mathrm{TiO}_{2}$ possesses three crystal polymorphs in nature: brookite, anatase and rutile (Ye and Ohmori 2002). Anatase is a metastable $\mathrm{TiO}_{2}$ polymorph, it tends to transform into the rutile upon heating, resulting in a loss of photocatalytic activity (Grzmil et al 2004). In thermal spray processes, the heat induced in the particle during spray can cause transformation of anatase to rutile. Due to this effect, the spray coatings usually contain more rutile with low photocatalytic properties (Yi et al 2008). Toma et al (2006) 
and Yang et al (2007) reported that the coating with $12 \cdot 6 \%$ and $55 \%$ by volume and anatase content could be deposited through gas fuel and HVOF spray of anatase $\mathrm{TiO}_{2}$.

In this paper, the coatings were deposited through a liquid fuel high velocity oxy-fuel spray with different fuel rates using $\mathrm{TiO}_{2}$ nanopowders as feedstock. The influence of the fuel rate on phase transformation of anatase to rutile, crystal size, morphology and photocatalytic activity of the coatings was investigated accordingly.

\section{Materials and experimental}

Degussa $\mathrm{P} 25 / 20 \mathrm{TiO}_{2}$ nanopowder was used as feedstock for the coating deposition. Commercially agglomerated and granulated nanopowders were used in this study. The average agglomerated size of the powder was $20 \mu \mathrm{m} .5 \times 50 \times 50 \mathrm{~mm}$ 316 Stainless steel plates were employed as substrates for the coating deposition. Prior to spraying, the substrate was blasted with silicon carbide grit.

Metjet III Metallization high velocity oxy-fuel (HVOF) system was used with kerosene as its fuel liquid. Powder was deposited using four sets of spray parameters which differed only in the flow rate of fuel and oxygen into the HVOF gun. The powder feed rate was $8 \mathrm{~g} / \mathrm{min}$ and carried by $\mathrm{N}_{2}$ at a flow rate of $4 \mathrm{~L} / \mathrm{min}$. Stand-off distance was maintained at $336 \mathrm{~mm}$ and the nozzle diameter was $11 \mathrm{~mm}$. Oxygen flow rate was fixed at $800 \mathrm{l} / \mathrm{min}$. Different fuel flow rates were employed as shown in table 1 . The morphology of the surface and crosssection of coatings was examined using S360 Cambridge Scanning Electron Microscope (SEM). TEM images were obtained using the LEO 912 transmission electron microscope that employed a tungsten electron gun in the voltage range of $120 \mathrm{kV}$ with an optical point to point resolution of $1 \mathrm{~nm}$. Samples were softly scraped-off from the substrate and examined by TEM. X-ray diffraction (XRD) patterns were recorded on a Philips PW3710 diffractometer using $\mathrm{CuK} \alpha$ radiation. After thermal spray, the percentages of anatase and rutile were calculated from X-ray diffraction intensities. The content of anatase $\mathrm{TiO}_{2}$ in the coatings was calculated by the following equation (Spurr and Myers 1957):

$$
A=1 /(1+1 \cdot 265(I R / I A)) \times 100,
$$

where $I A$ is the highest peak intensity of anatase phase $((101)), I R$ the highest peak intensity of rutile phase ((110)) and $A$ the content of anatase in the coatings. The crystallite size was evaluated from the X-ray diffraction patterns based on the Scherrer formula as shown in the following equation (Spurr and Myers 1957):

$$
t=(0 \cdot 9 \lambda) /(B \cos \theta),
$$

where $B$ is peak width at half maximum intensity, $\lambda$ the X-ray wavelength and $\theta$ the Bragg diffraction angle.

The photocatalytic performance of the coatings was determined by the degradation of methylene blue (MB) dye solution. The coated steel $(5 \times 5 \mathrm{~cm})$ was immersed into $35 \mathrm{ml}$ aqueous $\mathrm{MB}$ solution with a concentration of $10^{-5} \mathrm{~mol} / \mathrm{l}$ in a reaction cell. The cell was located in the photo-reactor ready for UV-irradiation having $5 \times 8$ watt black UV lamps, inducing the photochemical reaction to proceed. The coating/dye solution was irradiated in the horizontal direction and the distance between the UV lamp and the coating was kept within $20 \mathrm{~cm}$. The change of MB concentration in accordance with irradiation time was measured by UV-VIS spectrophotometer under UV irradiation. The photocatalytic degradation generally follows a Langmuir-Hinshelwood mechanism (Yu et al 2002).

$$
\operatorname{Ln}(C 0 / C)=t / \tau
$$

where $C$ is the concentration of the reactant (ppm), $C 0$ the initial concentration of the reactant (ppm), $t$ the irradiation time (h), and $\tau$ a constant of photocatalytic activity. According to (3), the smaller value of $\tau$, the better the photocatalytic activity of the coatings. Therefore, $\tau$ can be used as the characteristic decomposition time to evaluate the effectiveness of the sprayed coating in decomposing the pollutants.

\section{Results and discussion}

The crystalline structure of each of the coated test samples was studied by XRD analysis. It is generally assumed that the anatase metastable phase causes a higher photocatalytic degradation of the pollutants (Daniel et al 2008). Figure 1 shows the XRD patterns of $\mathrm{TiO}_{2}$ sprayed coatings and feedstock powder. The results have been summarized in table 1 . These results demonstrate that fuel flow rate influences the deposition characteristics such as the anatase content and anatase/ rutile average crystallite size. The peak belonging to $\mathrm{Fe}$ is due to the effect from the substrate. The thickness of the applied coatings was about $5 \mu \mathrm{m}$ so due to substrate peak

Table 1. Anatase content and anatase/rutile average crystallite size in different sprayed coatings.

\begin{tabular}{llcccc}
\hline Samples & $\begin{array}{l}\text { Fuel flow rate } \\
(\mathrm{mL} / \mathrm{min})\end{array}$ & Fuel-to-oxygen ratio & Anatase \% by volume & $\begin{array}{c}\text { Anatase crystallite } \\
\text { size (nm) }\end{array}$ & $\begin{array}{l}\text { Rutile crystallite } \\
\text { size }(\mathrm{nm})\end{array}$ \\
\hline Feedstock powder & - & & $75 \cdot 0$ & $25 \cdot 9$ & $41 \cdot 7$ \\
H1 & 120 & $0 \cdot 00015$ & $80 \cdot 0$ & $20 \cdot 7$ & $17 \cdot 3$ \\
H2 & 160 & $0 \cdot 0002$ & $78 \cdot 0$ & $25 \cdot 9$ & $17 \cdot 3$ \\
H3 & 200 & $0 \cdot 00025$ & $65 \cdot 8$ & $25 \cdot 9$ & $34 \cdot 6$ \\
H4 & 240 & $0 \cdot 0003$ & $8 \cdot 00$ & $25 \cdot 9$ & $41 \cdot 7$ \\
\hline
\end{tabular}




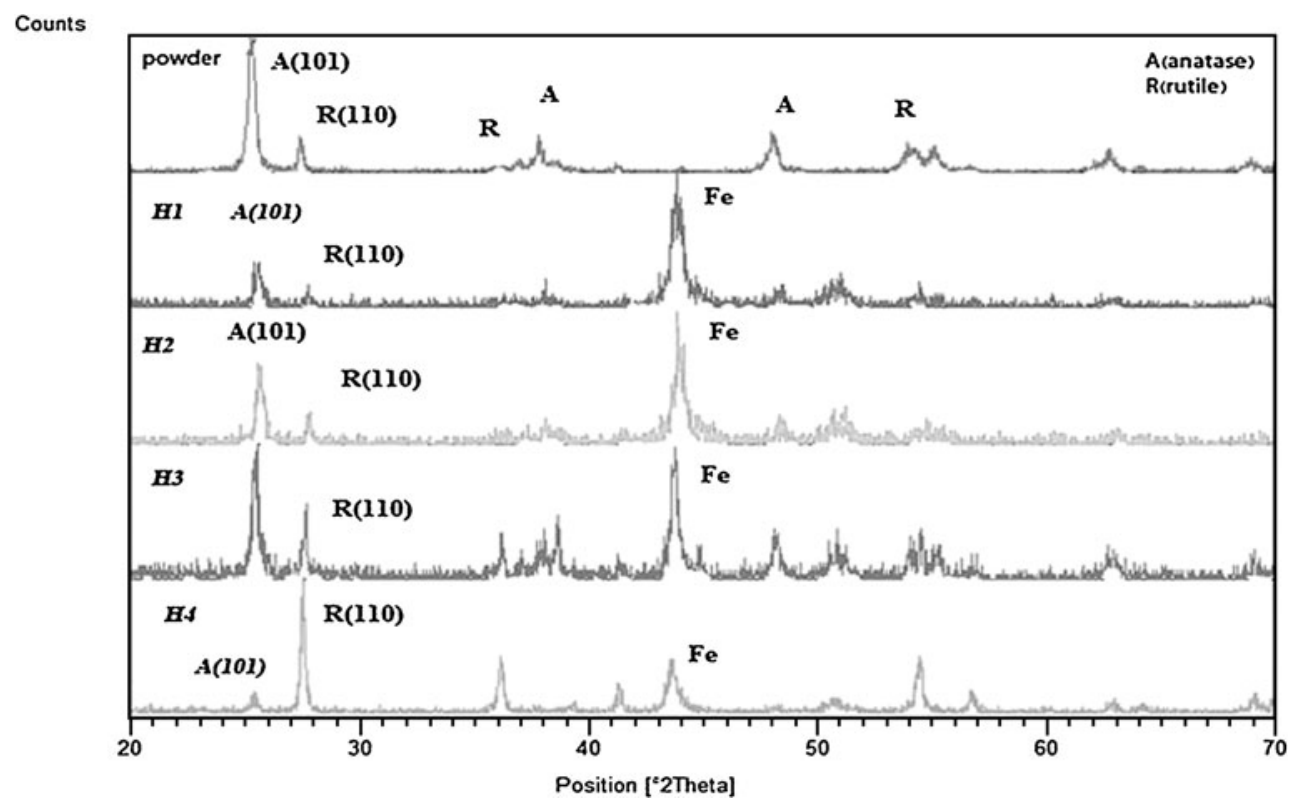

Figure 1. XRD pattern of feedstock powder and $\mathrm{HVOF}$ sprayed $\mathrm{TiO}_{2}$ coatings.
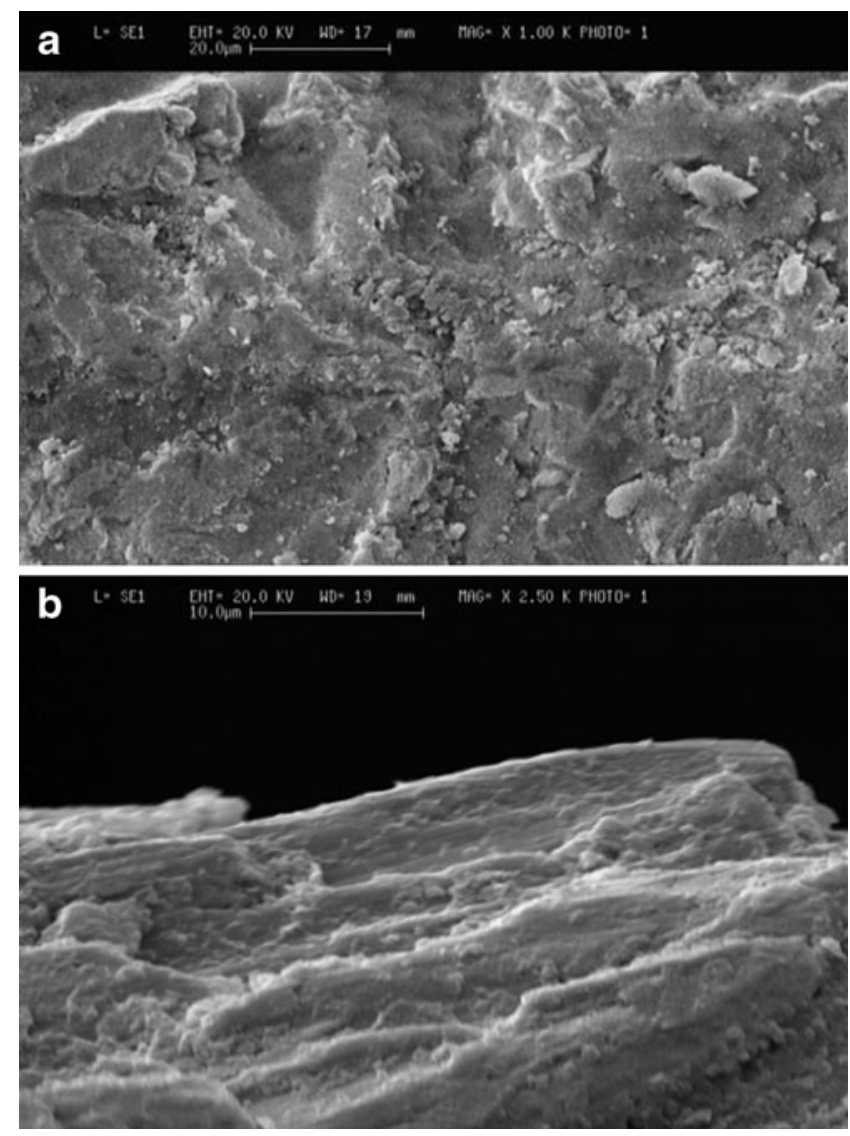

Figure 2. SEM images of a. surface and b. cross-section of $\mathrm{H} 1$ coating with $120 \mathrm{ml} / \mathrm{min}$ fuel flow rate.

the height of $\mathrm{TiO}_{2}$ peaks became low. It is assumed that the temperature and velocity of the powder particle prior to impact on the substrate or component surface and cooling rate of impacted droplets on substrate, will control the coating characteristics.
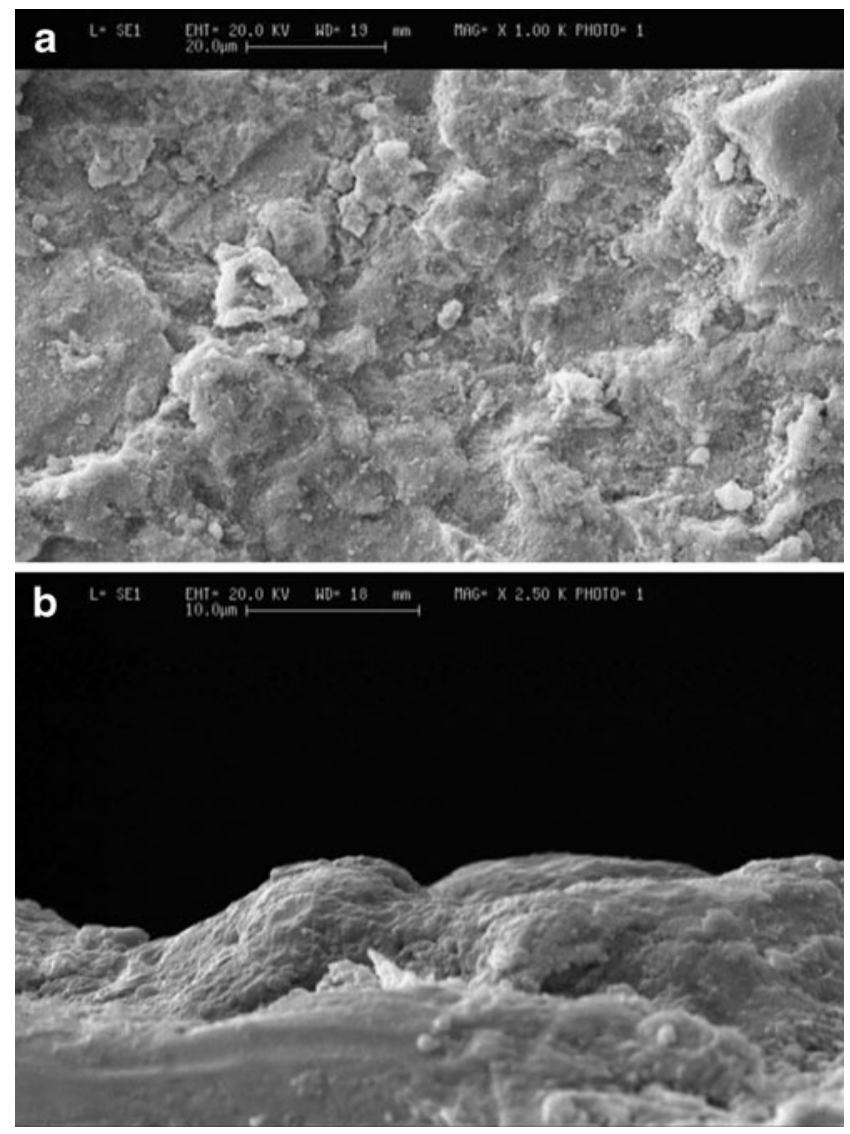

Figure 3. SEM images of a. surface and b. cross-section of $\mathrm{H} 4$ coating with $240 \mathrm{ml} / \mathrm{min}$ fuel flow rate.

Figures 2 and 3 present the SEM images of (a) surface and (b) cross-section of $\mathrm{TiO}_{2}$ spray coatings. It can be seen that there are two kinds of structures in the coating. One is the continuous molten phase and the other is a porous microstructure, which resulted from the existence of the 


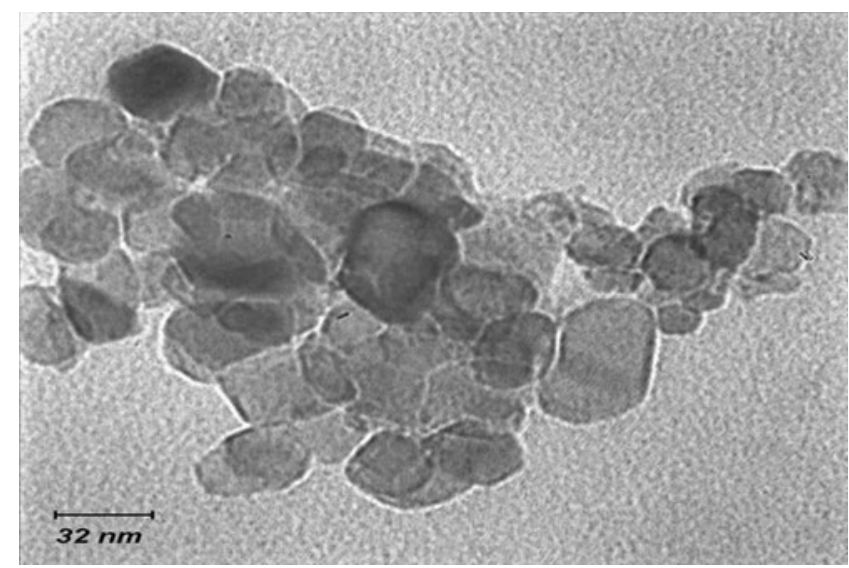

Figure 4. TEM image of $\mathrm{H} 1$ coating with $120 \mathrm{ml} / \mathrm{min}$ fuel flow rate.

non-molten or semi-molten starting powders. In H4 coating with $240 \mathrm{ml} / \mathrm{min}$ fuel flow rate, the porous structure increased as a result of higher fuel rate.

Figure 4 shows the typical TEM morphologies of the sprayed $\mathrm{H} 1$ coating with $120 \mathrm{ml} / \mathrm{min}$ fuel flow rate. The size of most grains in the $\mathrm{H} 1$ coating is $<30 \mathrm{~nm}$. The average grain size is about $20 \mathrm{~nm}$ which coincides with the grain size in the as-sprayed coatings measured by XRD.

In $\mathrm{H} 1$ and $\mathrm{H} 2$ coating with 0.00015 and 0.0002 fuel-tooxygen ratios, respectively the content of anatase reached $80 \%$ and $78 \%$ by volume, slightly more than the original feedstock powder content of $75 \%$ by volume. In the HVOF process, velocity of the torch is too high (about $1200 \mathrm{~m} / \mathrm{s}$ ) and its temperature is too low (about $2400^{\circ} \mathrm{C}$ ), respectively. Thus this high speed causes very little heat to flow into the in-flight particles, therefore, the degree of melting of particles becomes too low. Consequently, semi-molten (molten surface and non-molten cores) particles contain higher amounts of anatase than the fully molten particles (Yang et al 2004). As the particles impinge on the substrate the liquid fraction of droplet spreads to form a splat and solidified under a high cooling rate of about $10^{7}-10^{8} \quad{ }^{\circ} \mathrm{K} / \mathrm{s}$. Under such splat cooling conditions, metastable phases such as $\gamma-\mathrm{Al}_{2} \mathrm{O}_{3}$ in HVOF alumina, is easily formed in the coating (Mcpherson 1973). In agreement with the mentioned conclusions, the semi-molten $\mathrm{TiO}_{2}$ droplets can be solidified in an anatase form. The XRD results clearly indicated that the anatase phase was readily formed in the $\mathrm{TiO}_{2}$ deposited coating.

As the fuel flow rate into the gun increases whilst the oxygen flow rate remains constant in the sprayed coatings, the anatase content reached $80 \%$ by volume, $78 \%$ by volume, $65 \%$ by volume and $8 \%$ by volume, respectively. Thus the $\%$ anatase content had reduced as the fuel-to-oxygen ratio in the combustion chamber had increased, which causes a more significant explosion and resulting in higher torch temperatures. This higher explosion causes the torch velocity to increase due to a constant nozzle diameter, so by increasing the fuel-tooxygen ratio, both the temperature and torch velocity will be increased (Dolatabadi et al 2003).

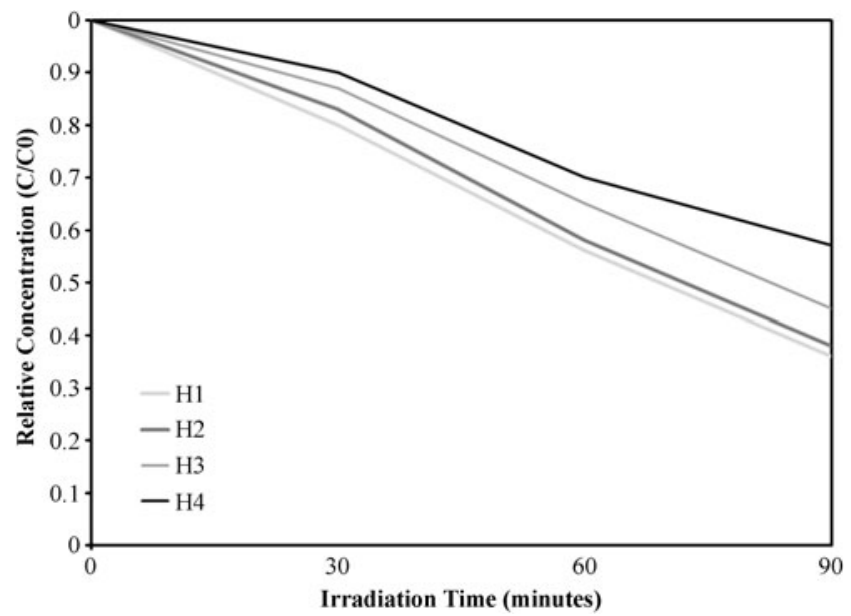

Figure 5. Degradation of $\mathrm{MB}$ by $\mathrm{TiO}_{2}$ coatings at different spray parameters as indicated in table 1 .

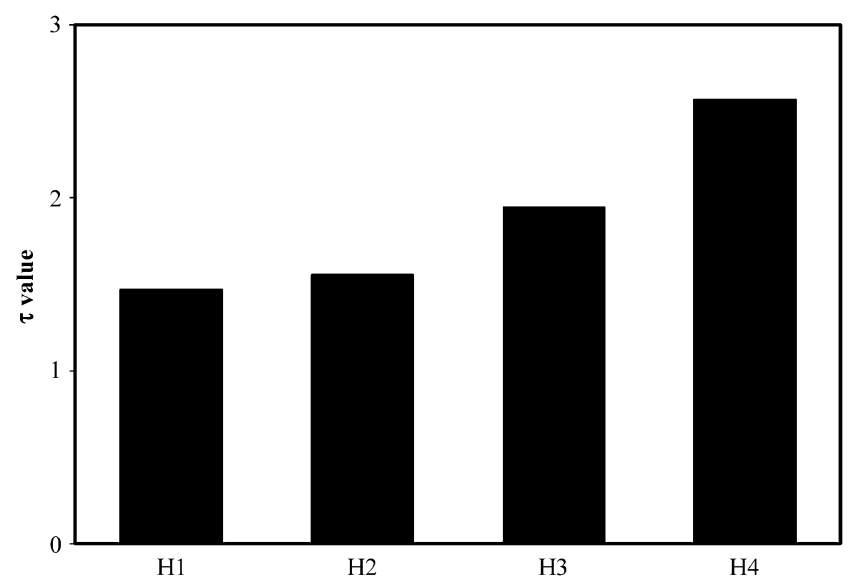

Figure 6. $\tau$ value of $\mathrm{TiO}_{2}$ coatings at different spray parameters as indicated in table 1 .

By increasing the fuel-to-oxygen ratio, the gas velocity at the exit of the nozzle changed very little compared to the change in the gas temperature ( $\mathrm{Li}$ and Christodes 2003) which on the one hand, created more semi-molten particles and on the other hand, caused a lower solidification rate of particle droplet on the substrate, consequently the rutile phase content in the coating increased. In coating with $240 \mathrm{ml} / \mathrm{min}$ fuel flow rate the anatase content drastically decreased compared with $200 \mathrm{ml} / \mathrm{min}$ fuel flow rate coating. As mentioned later, by increasing fuel flow rate the temperature and velocity of torch increased. This phenomenon has two effects, one, it causes higher degree of molten particles and, two, it also provides lower cooling rate of droplet on substrate. Probably in $240 \mathrm{ml} / \mathrm{min}$ fuel flow rate coating compared with $200 \mathrm{ml} / \mathrm{min}$, the degree of molten particles are too high, so high amount of anatase transforms to rutile during spray and also the cooling rate is too low to form anatase on substrate.

In the $\mathrm{H} 1$ coating, the average anatase/rutile crystallite size was $20 \cdot 7 / 17 \cdot 3 \mathrm{~nm}$ which is smaller than the feedstock powder which was $25 \cdot 9 / 41.7 \mathrm{~nm}$, respectively. It is assumed that a lower torch temperature, a lower degree of melting 
and a higher solidification rate creates the anatase in the particle cores and also forms anatase in coating during solidification on the substrate. The rutile present in the coating is probably due to the higher degree of melted particles and lower rate of solidification. The high solidification rate and high velocity impact of the particles on to the substrate would tend to break up the size of the anatase and rutile crystallites. In addition, significant rutile size reduction could also be the result of the rapid solidification of the particle droplets. In sprayed coatings with higher torch temperature, anatase/rutile crystallite sizes have been increased. Probably increasing torch temperature and decreasing solidification rate causes increase in the size of crystallites.

The HVOF $\mathrm{TiO}_{2}$ coatings were tested in the photocatalysis to evaluate their effectiveness for the degradation of MB. The decomposition characteristics of $\mathrm{MB}$ is illustrated in figure 5, as it is indicated in all the sprayed coatings that $\mathrm{MB}$ was decomposed. According to (3), the $\tau$ values of the sprayed $\mathrm{TiO}_{2}$ coatings under different spraying parameters were calculated, and then summarized in figure 6 . Lower $\tau$ values indicate a higher photocatalytic activity, so the $\tau$ value of the coatings with lower fuel flow rate, which is lower than the $\tau$ value of the coatings by higher fuel flow rate demonstrated a higher photocatalytic activity.

$\mathrm{TiO}_{2}$ absorbs ultraviolet rays and forms electron $\left(e^{-}\right)$and positive hole $\left(h^{+}\right)$. Hydroxyl radical $\left(\mathrm{OH}^{\circ}\right)$ is created from the positive hole and adsorption water. Some researchers have stated that some pollutants were decomposed by the hydroxyl radical (Sayilkan et al 2008). On the other hand, anatase $\mathrm{TiO}_{2}$ shows more efficient photocatalytic activity than rutile, so a lower anatase content ratio causes a lower photocatalytic performance. The photocatalytic activity of each of the sprayed coatings was different, which shows a behaviour dependent on the spray parameters. The different spray conditions cause different phase transformation of anatase to rutile and anatase content, respectively. The different photocatalytic performances in the degradation of the pollutants correlated mainly with the crystalline structure of the titanium coatings.

\section{Conclusions}

This paper proposed a study on the crystal structure, size, morphology and photocatalytic activity of $\mathrm{TiO}_{2}$ coatings obtained by high-velocity oxygen fuel spray methods with different fuel rates, using liquid fuel and agglomerated $\mathrm{TiO}_{2}$ nano-powder as feedstock material.

The coating obtained by the HVOF technique was characterized by the crystal structure, size, morphology and photocatalytic activity that was obtained by XRD, SEM, TEM and degradation of MB under UV irradiation. The as-sprayed $\mathrm{TiO}_{2}$ coating was composed of different contents of anatase and rutile phases obtained by different fuel ratios. HVOF spraying parameters were found to influence the coating quality. A lower fuel-to-oxygen ratio equivalent to $0 \cdot 00015$ is the preferred coating parameter to provide a high anatase content of $80 \%$ by volume. This coating has higher photocatalytic activity. This high anatase content in the coating is attributed to the retention of the anatase in the starting powder and also from forming anatase from the molten particles due to its rapid solidification. Furthermore, the preferred HVOF sprayed coatings presented a smaller crystallite size than the corresponding original powders. It can be concluded that the HVOF spraying with kerosene fuel and an optimum fuel-to-oxygen ratio is an appropriate technique to create photocatalytic $\mathrm{TiO}_{2}$ surfaces with a high anatase ratio and nanostructure morphology.

\section{References}

Daniel L M, Frost R L and Zhu H Y 2008 J. Colloid \& Interface Sci. 322190

Dolatabadi A, Mostaghimi J and Pershin V 2003 J. Mater. Proc. Technol. 37214

Grzmil B, Kic B and Rabe M 2004 Chem. Pap. 58410

Hearley J A and Little J A 2000 Surf. Coat. Technol. 123210

Kamnis S and Gu S 2006 Chem. Eng. Sci. 615427

Kanazawa T and Ohmori A 2005 Surf. Coat. Technol. 19745

Kim G E 2007 Nanostruct. Mater. 91

Li M and Christodes P D 2003 Chem. Eng. Sci. 58849

Mcpherson R 1973 J. Mater. Sci. 8851

Sayilkan F, Asiltürk M, Tatar P, Kiraz N, Şener S, Arpac E and Sayilkan H 2008 Mater. Res. Bull. 43127

Spurr R A and Myers H 1957 Anal. Chem. 29760

Toma F L et al 2006 Mater. Sci. \& Eng. A417 56

Yang G J, Lia C J, Hana F and Ohmori A 2004 Thin Solid Films 46681

Yang G, Li C, Wang Y and Li C 2007 Surf. Coat. Technol. 20263

Ye F and Ohmori A 2002 Surf. Coat. Technol. 16062

Yi Z, Guofeng C, Ma W and Wei W 2008 Prog. Org. Coat. 61321

Yu J, Zhang L and Ho W 2002 J. Photochem. Photobiol. A: Chem. 148263 